\title{
REIFICAÇÃO, REPRESENTAÇÃO E INSTANCIAÇÃO: GEORG LUKÁCS CONTRA SEUS INTÉRPRETES
}

\author{
Timothy Bewes
}

Disputas sobre a utilidade do termo "reificação" têm sido frequentemente acompanhadas por insinuações sobre sua propensão a estar na moda1. "Na moda", nesta equação, descreve o declínio de um conceito ao próprio processo que ele descreve: uma "coisa". Entretanto, os dois termos estão tão imbricados que há muito tempo é difícil dizer qual está mais na moda: a reificação ou a sua rejeição devida ao fato de estar na moda. Por um tempo, pareceu que qualquer novo acerto de contas com o conceito de reificação teria que lidar com essa inseparabilidade ou reversibilidade entre a reificação e a ansiedade em relação a ela. ${ }^{2}$ Mas intervenções recentes no assunto tornaram necessária uma atenção renovada à diferença entre reificação e a sua aprovação pelas próprias forças que ela descreve. A reificação, em suma, está de volta "à moda" com uma vingança.

${ }^{1}$ Louis Althusser referiu-se pela primeira vez à "completa e moderna teoria da reificação” em For Marx (ALTHUSSER, 2005, p. 23on). Žižek referiu-se ao termo como um de um número de motivos no livro de Lukács História e consciência de classe, que provou ser passível de apropriação por "críticos conservadores da 'sociedade de consumo"” (ŽIŽEK, 200o, p. 153). O próprio Lukács descreveu tais motivos como "noções modernas" em seu prefácio de 1967 à reedição do livro (LUKÁCS, 1971, p. xxxviii).

${ }^{2}$ Este é o tema de meu livro Reification, or The Anxiety of Late Capitalism (London: Verso 2002). 
São conjuntamente responsáveis por (ou sintomáticos de) uma reaparição do interesse por esse conceito: a publicação, em 2008, das Tanner lectures de 2005 de Axel Honneth, acompanhada de respostas de três comentadores eminentes; a aparição do livro The reification of desire: toward a queer Marxism (2009) de Kevin Floyd; o retorno de Fredric Jameson à questão da reificação em dois livros recentes, Valences of the dialectic (2011) e Representing capital (2011); um ensaio sobre o mesmo tópico pelo crítico literário Bill Brown (2006); assim como uma crescente literatura secundária sobre todos esses trabalhos. O recorte desses projetos difere amplamente; tomados de modo coletivo, eles oferecem concepções surpreendentemente variadas do termo central. Todos fazem referência a Lukács, o principal pensador do conceito, mas cada um tem uma ideia diferente do que ele define como reificação, e o que pode ser resgatado de sua teoria; cada um, portanto, apresenta um modelo diferente de como a reificação pode ser relacionada a uma crítica da relacionabilidade capitalista. Para qualquer um que conheça este campo a fundo, a variedade de possíveis leituras ou apropriações de Lukács é, de fato, impressionante. Trata-se de uma consequência, talvez, do fato de ter existido pouco ou nenhum diálogo sustentado entre esses autores.

O objetivo deste ensaio é, em parte, estabelecer os termos para tal diálogo ao focar duas questões centrais: (i) a representação é possível sem a reificação? e (ii) existem casos de reificação? Argumentarei sobre as diferenças nas posições sobre reificação representadas por estes pensadores e críticos (com os quais não será possível lidar a fundo e completamente), e as respostas deles sobre as questões aqui colocadas. Tais respostas requerem um trabalho de desvendamento, pois elas envolvem uma conceitualização da reificação em relação a dois conceitos adjacentes porém não teorizados e não reconhecidos, representação e instanciação. Focarei aqui os trabalhos de Axel Honneth e Kevin Floyd, dois pensadores muito diferentes, cujos projetos para racionalizar e atualizar o conceito de reificação estão fundados, como irei argumentar, no próprio problema que muito frequentemente tem sido responsável por ler equivocadamente o ensaio de Lukács sobre a reificação: o de tomar a reificação como uma categoria representacional, em vez de tomá-la como uma categoria puramente lógica.

Um efeito esperado desta investigação é a recuperação de um uso relativamente neutro do termo "representação" - prevenindo o que Jacques Rancière descreveu como sua "inflação" ética e ontológica, na qual certos fenômenos (a Shoah, o sublime kantiano, o próprio capitalismo) acabam envolvidos no que ele chama deum "terror sagrado" da irrepresentabilidade 
(RANCIÈRE, 2007, p. 109). Um segundo efeito será a entrada em foco de um novo conceito: a instanciação. Esta elucidação irá se iniciar, portanto, com um esclarecimento do significado de Lukács de "reificação" em relação a esses dois termos, os quais abordarei respectivamente por meio das questões acima articuladas.

\section{A REPRESENTAÇÃO É POSSÍVEL SEM A REIFICAÇÃO?}

Em primeiro lugar, a reificação não tem relação intrínseca com a representação. Esta reivindicaçãovai deencontroa explicações dereificação dominantes, incluindo, mais notavelmente, o reenquadramento recente de Axel Honneth do termo para significar a falha do reconhecimento (em outras palavras, a injustiça representacional em relação ao outro). Para Lukács, reificação não significa a representação (ou a falha da representação, erro na percepção ou no tratamento) de seres humanos como "coisas". Reificação designa um evento lógico, não um evento representacional. A reificação não é parte de uma abordagem crítica pressuposta a partir da representação do mundo; não é uma ferramenta crítica disponível "ao alcance da mão", mas uma problemática: uma categoria de pensamento que está implicada em seu próprio conceito, que deve incluir a si mesma entre seus objetos de crítica.

Se a reificação, como defenderei, permanece a melhor explicação teórica da lógica do capitalismo, essa lógica é mais bem concebida como um evento não de representação (falha na representação, falha de reconhecimento etc.) mas um evento do ser. A reificação não descreve a percepção de uma entidade particular em uma forma que não seja a de sua real existência, mas a postulação mesma daquela entidade como existente. A representação é possível sem a reificação, mas para que assim seja, a representação deve ser concebida e empreendida separadamente de qualquer processo de instanciação. $\mathrm{O}$ momento da reificação é a instanciação da coisa enquanto tal - e esse momento ocorre independentemente de qualquer momento de representação.

Podemosconfirmar isto, de maneira preliminar, relendoos parágrafos de abertura do ensaio de Lukács sobre reificação, nos quais ele descreve a premissa do fenômeno da reificação. Como todos sabem, o seu modelo de exposição é resultado da estrutura das mercadorias no primeiro capítulo do Capital de Marx. A base da estrutura das mercadorias, escreve Lukács (1971, p. 83), "é que a relação entre as pessoas toma caráter de coisa e, portanto, adquire uma 'objetividade fantasma', uma autonomia que parece tão estritamente racional e envolvente a ponto de esconder 
todo vestígio de sua natureza fundamental: a relação entre pessoas”. Os termos importantes nesta passagem são a palavra "relação", na primeira metade da frase, e a expressão "objetividade fantasma”, na segunda. A reificação, para Lukács, não envolve a transformação de pessoas em coisas, mas a transformação das relações entre as pessoas em coisas (id., ibid.) $)^{3}$.

${ }^{3}$ Neste momento, a própria teorização de Lukács parte significantemente da teoria do fetichismo da mercadoria de Marx. "No ato de enxergar", escreve Marx (traçando uma analogia com a percepção visual que Lukács não retoma), "a luz é de fato transmitida de uma coisa, o objeto externo, a outra coisa, o olho. É uma relação física entre coisas físicas. A forma da mercadoria e a relação de valores dos produtos de trabalho nas quais aparece, enquanto oposta a isso, não tem absolutamente nenhuma conexão com a natureza física das relações da mercadoria e das relações materiais [dinglich] surgindo disto. Trata-se da relação social definitiva entre os próprios homens que assume aqui, para eles, a fantástica forma de uma relação entre coisas" (MARX, 1990, p. 165). A mudança identificada em Marx não é de relações a coisas, portanto, mas de relações entre homens a relações entre coisas. Isto não quer dizer, de qualquer modo, que Marx está descrevendo uma transformação de homens em coisas; trata-se, aqui, da transformação de um tipo de relação (digamos, de necessidade e o seu cumprimento) em outra (aquela do valor, isto é, fungibilidade). O que parece, portanto, ser um deslize na leitura de Marx por Lukács deve ser entendido como a inovação de um conceito inteiramente novo, distinto do fetichismo das mercadorias. Não existe, na verdade, nenhum conceito de reificação nos escritos maduros de Marx. Mais tarde, no Capital, Marx de fato fala sobre "a conversão de pessoas em coisas" na troca de mercadorias (MARX, 1990, p. 209); mas ele refere-se à metamorfose da mercadoria com sua entrada em circulação. A contradição inerente a esse processo torna-se aparente no momento da mediação da troca através do dinheiro, na qual os objetos são "personificados" (por exemplo, eles representam, substituem o vendedor), enquanto pessoas são convertidas em (p. ex., são representadas por) coisas que esperam se adquiridas, sob a forma do comprador. A “reificação” aqui (embora Marx use o termo Versachlichung "objetificação") é inteiramente simbólica e provisória. Marx nunca a utiliza para descrever a percepção, representação ou o tratamento de trabalhadores ou consumidores no modo capitalista de produção. Quando Lukács utiliza o termo naquele contexto, "reificação" (agora Verdinglichung) igualmente não se refere ao próprio trabalhador, mas, por exemplo, à maneira pela qual seu tempo e de fato a sua "personalidade humana total" são abstraídos em sua "performance”. Isto é parte da lógica do modo de produção; ele não diz absolutamente nada sobre o modo como o(a) trabalhador(a) é considerado ou mesmo tratado por seu empregador. Quando Althusser, rejeitando a "famosa teoria da reificação", aponta (corretamente) que "uma categoria mais estranha para Marx [que coisa] não pode ser imaginada” (ALTHUSSER, 2005, p. 230n), ele está, portanto, mais perto do Lukács de História e consciência de classe do que parecia se dar conta. "Não é com a brutalidade de uma simples 'coisa' que o homem se depara quando está em relação direta com o dinheiro", escreve Althusser, "é com um poder (ou a falta dele) sobre coisas e homens". Esse "poder (ou a falta dele)" é precisamente o que, para Lukács, constitui a lógica da reificação. Fredric Jameson também foi assíduo em esclarecer o uso de Lukács do termo, afirmando que quando a reificação se torna "uma propriedade de objetos" a própria teoria da reificação "torna-se reificada”, parecendo "bloquear aquele nível de trabalho de produção do qual foi, antes, uma parte integral" (JAMESON, 2011b, p. 27-28). 
A diferença entre estas duas propostas é grande, decisiva. Vários autores que tratam da reificação reconhecem a diferença, mas depois discutem o conceito como se a diferença não existisse ${ }^{4}$. A reificação não descreve, por exemplo, o efeito direto de práticas trabalhistas exploradoras do povo (embora tais práticas sejam endêmicas ao capitalismo, e certamente envolvam reificação); ela diz respeito à lógica dessas práticas, segundo as quais processos e relações são substituídos por entidades abstratas. Para Lukács, a reificação não é um modo de tratar as pessoas (por exemplo, como se elas fossem "coisas"); ela não denota uma má "atitude", ou um "hábito de pensamento" corrigível. A "coisa" na frase de Lukács não é uma pessoa, tomada em menor consideração enquanto componente em um processo de produção que, digamos, um ser humano; ela é a abstração, a entidade abstrata que emerge na forma de um ser humano enquanto tal, não mais visto em suas relações com outros, mas como "autônomo" 5 . A reificação é a lógica do ser-objeto em si. O "fantasma da objetividade" atribuído a qualquer pessoa enquanto entidade individual constitui o momento mais enigmático e intratável da reificação.

Para que a representação aconteça sem a reificação, portanto, é necessário separar o ato da representação da lógica da instanciação. A instanciação é um evento no qual uma entidade (uma pessoa, um objeto, um signo linguístico, um encontro, uma descrição fictícia,

${ }_{4}^{4}$ Tais pensadores incluem Honneth, que cita a mesma frase de Lukács, mas termina a citação depois da palavra "coisa" - omitindo, portanto, a referência crucial à "objetividade fantasma" e a "uma autonomia que parece tão estritamente racional e envolvente a ponto de esconder todo traço de sua natureza fundamental” (LUKÁCS, 1971, p. 21). Outra versão da mesma falácia aparece no trabalho anterior de Peter Berger e Thomas Luckmann, para os quais a reificação é grosseiramente equivalente à mistificação, e desreificação à secularização (BERGER e LUCKMANN, 1967, p. 107). Em ambos os casos, a reificação é entendida como um processo de mão-única, uma entidade identificável e diagnosticável em si mesma. Mais recentemente, o crítico literário americano Bill Brown, influenciado pelo trabalho cultural-antropológico de Arjun Appadurai, refere-se em um ensaio de 2005 à "reificação humana (onde as pessoas parecem ser nada além de coisas)" (BROWN, 2006, p. 180). Brown também elucida um ensaio do antropólogo Igor Kopytoff (1986), para o qual a escravidão é o caso exemplar de ambas mercantilização e reificação: o tratamento de pessoas como objetos. Esta compreensão de reificação - como Honneth a define, uma compreensão "literal" (HONNETH, 2008, p. 148) - está muito distante daquilo que Lukács pretende com o termo. Vale a pena lembrarmo-nos, especialmente à luz do trabalho de Kopytoff e de seu uso por Brown, que a escravidão - neste contexto, como tráfico humano e racismo - não é, para Marx, uma formação capitalista, mas uma formação pré-capitalista, um exemplo da barbárie que o capitalismo irá superar (MARX, 1988, p. 59).

5 Isto é também o que Jameson (2011b, p. 27) quer dizer quando insiste que a reificação é um "processo figurativo, não importa o quão real ou social também possa ser". 
um traço de caráter) é afirmada como um caso ou instância de uma categoria, propriedade ou conceito maiores, cuja realidade ela supostamente comprova. Naturalmente, qualquer discurso ou registro normativo, não importa o quão politicamente significante, participa da instanciação a todo momento. A instanciação representa uma forma de entrada na existência que nega ou compromete a singularidade de qualquer entidade como a descrita acima. Estar atento à "instanciação", portanto, é registrar uma discrepância ou um vão internos ao próprio ser. Nos termos de Heidegger (1962, p. 229), a instanciação denota o "estar-lançado" do ser, ou a "fuga [da existência] face a si mesma". A instanciação, parafraseando Alain Badiou (2007, p. 64), está implícita em "cada densidade, cada reivindicação à substancialidade, e cada asserção da realidade". Quando Badiou formula o que ele chama de um "protocolo subtrativo", um procedimento crítico que procura extrair o real da "realidade que o envolve e o esconde", um conceito de instanciação, sem nome e sem teoria, está operando no coração deste pensamento. Badiou - traduzindo o seu trabalho em termos que ele nunca usa - entende a instanciação como a lógica verdadeira da reificação. Ao longo deste trabalho usarei a fórmula representação sem instanciação para descrever a possibilidade de representação não-reificada - uma afirmação futura, que não tenho espaço para desenvolver aqui, é que outro termo para representação sem instanciação é "literatura".

\section{EXISTEM CASOS DE REIFICAÇÃO?}

Uma implicação direta da redefinição de reificação como instanciação é a de que "casos" de reificação não existem - não porque as relações capitalistas são irrepresentáveis ou não-instanciáveis (elas não são nenhum dos dois), mas porque a reificação designa a lógica inerente a essas relações. Isolar "casos" de reificação significa suprimir a qualidade da reificação enquanto lógica: o efeito desta supressão é que um conceito (reificação) designado para lembrar-nos do quanto somos atravessados e formados por processos e relações é transformado em seu oposto. Tomemos, por exemplo, a seguinte discussão do "namoro virtual", um fenômeno que, de acordo com o escritor, muito provavelmente levará ao que ele chama de "autorreificação":

Este modo padronizado de entrar em contato com potenciais parceiros compele os usuários a descrever as suas características pessoais de acordo com [...] rubricas pré-determinadas e pré-calibradas. [...] Não é necessária uma 
imaginação superativa para conceber como isto pode promover uma forma de autorrelacionamento na qual um sujeito não mais articula os seus desejos e intenções em um encontro pessoal, mas é meramente forçado a reuni-los e comercializá-los de acordo com os padrões do processamento acelerado de informação. (HONNETH, 20o8, pp. 83-4).

A implicação desta passagem é a de que os próprios "desejos e intenções" do sujeito, antes de sua inserção nas "categorias prescritas", estão livres de reificação. A sua base metafísica é uma oposição entre "seres humanos" não-reificados (junto com a sua "humanidade" originalmente não-reificada, mas sempre reificável) e reificados - isto é, não-humanos ou desumanizados - "coisas". A lógica da reificação é, deste modo, preservada na "objetividade fantasma" que é atribuída aos próprios seres humanos. Ilustrar a lógica da reificação usando-se tais "casos" é, portanto, participar desta lógica. Trata-se de falhar ao alcançar o nível ao qual a reificação satura a operação, a experiência e a percepção do capitalismo; conceber mal a reificação em termos de representação, mais do que instanciação.

\section{REIFICAÇÃO COMO NÃO-RECONHECIMENTO}

A figura que mais publicamente exibe os erros que estou descrevendo é o filósofo e teórico social alemão Axel Honneth, cujo Reification: a new look at an old idea, primeiro publicado em inglês como as Tanner lectures em Berkeley em 2005, é a fonte da passagem supracitada sobre namoro virtual. Honneth resume a concepção de Lukács de reificação desta forma: "O conceito [de reificação] [...] designa uma ocorrência cognitiva na qual algo que não possui características típicas de coisa em si (p. ex., algo humano) passa a ser visto como uma coisa" (HONNETH, 2008, p. 21). Em outra passagem, ele escreve: "Reificar outros humanos significa simplesmente negar a sua existência enquanto humanos” (id., p. 76). Este deslize do registro lógico no registro representacional tem sido uma falácia das considerações sobre reificação desde a aparição do ensaio de Lukács; ele erra na identificação do objeto de reificação (precisamente porque o identifica, separando a reificação de seu objeto), invertendo, desta maneira, o seu significado. Honneth, assim, transforma um termo figurativo, que denota um evento lógico, em um termo "literal", que denota um evento perceptivo (ou representativo).

"Lukács," diz Honneth (2008, p.25), “entende 'reificação' como sendo um hábito de mera contemplação e observação, no qual o âmbito natural, o ambiente social e as características pessoais do indivíduo 
passam a ser apreendidos de maneira imparcial e sem emoção - em suma, como coisas". Mas não é assim que Lukács entende a reificação. Não há nada necessariamente "desprendido e sem emoção" sobre a "instância contemplativa” na qual homense mulheresvivenciam o mundo; Lukács não diz absolutamente nada sobre o seu caráter afetivo ${ }^{6}$. A importância desta experiência "coisal" é que o mundo é apresentado "independentemente da consciência do homem e [como] impenetrável à intervenção humana"; isto é, é experienciada em seu ser. O processo é o de uma lógica na qual, como Lukács diz, "as mais básicas categorias da atitude imediata do homem para com o mundo" são transformadas; espaço e tempo são reduzidos a "um denominador comum," o que significa que o tempo passa a ser experienciado espacialmente (LUKÂCS, 1971, p. 89 e p. 93). Para dizer com outras palavras, o tempo é instanciado; ele avança enquanto tal, torna-se mensurável, contável e permutável. Nos termos de Marx (citado por Lukács), o homem torna-se "a encarnação do tempo" (id., p. 99). A versão de reificação exposta por Honneth, por contraste - um fenômeno reconhecível -, não é nada além de um espelho no qual contemplamos nossa própria "imediaticidade autêntica" (id., p. 93); a reificação torna-se um fenômeno objetivo, isolável e perceptível; mas esta perceptibilidade mesma é um exemplo de como, para Lukács, "a estrutura da reificação progressivamente penetra de modo cada vez mais profundo, fatal e definitivo na consciência do homem." A análise de Honneth se assemelha à apreensão burguesa da reificação que Lukács condena por focar-se nas "formas as mais externas e vazias", separando-as de "sua real fundação capitalista”, tornando-as, assim, "independentes e permanentes" (id., p. 94-95). O que está sujeito à reificação, na compreensão de Honneth, são, em primeiro lugar, as pessoas - o que implica que ser completamente uma "pessoa" é, por definição, estar livre de reificação. A reificação torna-se um fenômeno representacional; ela denota uma falha de "reconhecimento" uma falha, diz Honneth (2008, p. 148), "ao perceber as características que tornam essas pessoas instâncias da espécie humana em qualquer sentido verdadeiro".

O uso do termo "instância" aqui é especialmente significativo por revelar o abismo entre o trabalho de Honneth e a leitura de Lukács apresentada neste artigo. Pois a "instanciação" de um indivíduo em termos

${ }^{6}$ Em seu livro, Honneth (2008, p. 27) introduz o termo "comprometimento empático" como uma paráfrase do que, para Lukács, está faltando na consciência reificada, mas subsequentemente trata a frase como se fosse uma citação (id., p. 35, p. 54 e p. 55). De fato, como qualquer leitor de Lukács sabe, a noção de empatia ou simpatia é completamente estranha ao pensamento de Lukács. Ambos os termos não aparecem em nenhuma parte de História e consciência de classe. 
de sua "humanidade" é precisamente tão reificante quanto uma negação desta categoria poderia ser, talvez não mais, mas com certeza não menos. Igualmente, os "desejos e intenções" do exemplo dado por Honneth sobre o namoro virtual, antes de sua inserção nas categorias padronizadas da agência de namoros, evidenciam a lógica da reificação tanto quanto o momento posterior da inserção. O "fantasma da objetividade" da reificação, para retornar à expressão de Lukács, é principalmente uma lógica humanista, não uma lógica materialista ou maquinal ${ }^{7}$.

O capitalismo contemporâneo não é, em sua maior parte, reificante no sentido dado por Honneth; ele não trata os trabalhadores como "coisas"; de fato, ele os trata, os instancia, como seres humanos livres. Slavoi Žižek articulou isto de modo correto em seu discurso no protesto Occupy Wall Street, em Nova Iorque, outubro de 2011: "Nós temos todas as liberdades que queremos. Mas o que nos falta é [...] a linguagem para articular a nossa não-liberdade. $\mathrm{O}$ modo como somos ensinados a falar sobre liberdade - guerra ao terror e assim por diante - falsifica a

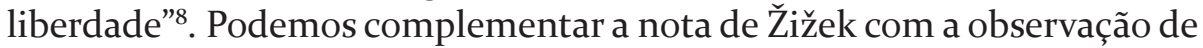
que o que "falsifica" a liberdade é precisamente a compulsão de falar-se sobre ela. A pressão que o movimento "Occupy" sofreu para nomear as suas demandas em termos positivos, para elaborar um programa - ou, nas palavras de Žižek, para articular a sua não-liberdade -, deve ser entendida como a pressão para aderir a uma lógica capitalista que pode acomodar cada desejo e necessidade desde que seja possuída, proclamada e habitada por uma posição subjetiva identificável.

${ }^{7}$ A questão do "humanismo" de Lukács (e de Marx, no início) é, com certeza, uma grande questão. Apesar do fato de tanto Marx quanto Lukács com frequência usarem os termos "humano" e "humanismo" para denotar aquilo que é empobrecido pelo capitalismo, não há necessidade de ler o conjunto da obra de nenhum dos dois como "humanista" em sua orientação. Por essa razão, e mesmo defendendo completamente a sua crítica meticulosa da concepção de reificação de Honneth, não compartilho a ênfase do trabalho de Andrew Feenberg (2011, p. 102), de acordo com o qual a reificação é mais bem lida como uma "teoria crítica da tecnologia". A crítica de Feenberg a Honneth foca-se na negligência deste quanto à "predominância de estruturas racionais que distorcem e oprimem as vidas humanas que contêm”. O próprio Feenberg, em contraste, enfatiza o papel da reificação na "distorção" e na "opressão" nas vidas que ela afeta. Feenberg, portanto, reproduz a própria junção de Honneth da reificação com o tecnológico, e da existência não-reificada com a natureza ou o humano.

${ }^{8} \mathrm{O}$ texto citado provém da transcrição do discurso de Žižek na maneira como foi pronunciado (2011a). Para o texto preparado para o discurso, cf. 2011b. No trabalho previamente publicado que Žižek estava usando como base para esse discurso - a introdução ao seu Welcome to the desert of the real -, Žižek adiciona a seguinte observação esclarecedora: "As nossas próprias 'liberdades' servem para mascarar e sustentar a nossa não-liberdade mais profunda” (ŽIŽEK, 2002, p. 2). 
Um dos momentos mais desconcertantes no texto de Honneth ocorre quando ele menciona o racismo como um dos vários "casos de reificação" que Lukács supostamente "ignora”, devido ao seu "preconceito segundo o qual apenas as forças econômicas podem levar a uma negação das características humanas dos humanos". O racismo, para Honneth (2008, p. 78), é uma forma de "desumanização bestial" que não tem nada a ver com a "troca capitalista de mercadorias". De maneira ainda mais surpreendente, ele faz a mesma alegação sobre o "tráfico humano". Tais fenômenos são mais bem explicados, segundo Honneth (2008, p. 79), como o resultado de "adotar uma visão de mundo ou ideologia específicas". É inevitável tentar supor o que Honneth deve conceber como relação econômica, assim como perguntar-se sobre a completa ausência, em sua análise sobre a reificação, de qualquer teoria da ideologia. A passagem exemplifica a subjetividade que atravessa a análise de Honneth, de acordo com o qual as "convicções" ideológicas (o que ele chama de "esquemas do pensamento") são meramente outra "fonte social" da reificação, ao lado das, digamos, forças econômicas (id., p. 59).

A reificação, devemos ser claros, pode aplicar-se tanto ao sentimento antirracista quanto à consciência racista. A reificação caracteriza a existência de alguém tanto quanto, ou mais que, a "pretensão" de ser alguém; ela implica a autoconcepção de um indivíduo tanto quanto o mesmo refletido nos olhos de outro9. Reificação não é um modo de percepção ou representação, mas uma lógica cuja relevância é ilimitada e sempre reversível. Esta reversibilidade é perdida, ou ameaçada, quando deduzimos e tipificamos "casos" de reificação ${ }^{10}$. Honneth (2005, p. 65) oferece um número de tais "casos" [Fälle], designados a ilustrar a sua reconceitualização da reificação como a falha do "reconhecimento antecedente" do outro, ou a falha do "compromisso empático".

Dequalquer modo, faceà crítica dirigida a algumas de suas ilustrações, até mesmo Honneth reconheceu a sua inadequação. $\mathrm{O}$ exemplo mais notável é o da jogadora de tênis "que, em seu foco ambicioso em vencer, esquece que a sua oponente é, de fato, a sua melhor amiga, por cuja causa ela começou a jogar em primeiro lugar" (HONNETH, 2008, p. 59). Em sua "Tréplica" aos comentários por Judith Butler, Raymond Geuss e Jonathan Lear, publicada na tradução inglesa de seu livro, Honneth reconhece

\footnotetext{
${ }^{9}$ Para uma crítica explícita de Honneth nestas áreas, cf. Larsen, 2011, esp. p. 81-82. Para um corretivo importante à visão de Honneth sobre o racismo, embora seja anterior à obra de Honneth por quase 40 anos, cf. Gabel, 1975, p. 119-136.

${ }_{10}$ Escrevi mais longamente sobre a "reversibilidade" da reificação em Bewes, 2002, especialmente p. 201-214.
} 
que o exemplo "inofensivo" da jogadora de tênis falhou em mostrar "as consequências da reificação". Ele oferece um exemplo alternativo que, comparado ao da jogadora de tênis, parece sobredeterminado: "a atividade da guerra", uma atividade na qual

\begin{abstract}
o propósito da aniquilação se torna tanto um propósito em si mesmo que, mesmo na percepção daqueles não diretamente envolvidos (p. ex., mulheres e crianças), toda a atenção às qualidades do ser humano é perdida. No final, todos os membros dos grupos presumidos como inimigos passam a ser tratados como objetos sem vida, com aspecto de coisas, que merecem ser assassinados e maltratados. [...] Neste caso, cada resquício de ressonância emocional parece ter desaparecido tão completamente que não podemos nem rotular isso como indiferença emocional, mas somente como 'reificação' (HONNETH, 20o8, p. 59 e p. 155-156).
\end{abstract}

De acordo com a leitura de Honneth, Neil Larsen (2011, p. 82) observa de modo incisivo: "um ato apaixonado de troca de mercadorias iria [...] escapar à reificação". Pode-se fazer uma observação similar sobre o exemplo da guerra: presumivelmente, as atrocidades cometidas com uma estratégia ou lógica militar compreensíveis não poderiam ser acusadas de reificação sob o sentido que Honneth lhe dá.

Avançando uma categoria da qual é uma instância, o "caso" participa da reificação - mesmo se a categoria em questão é a reificação: isto é o que se entende por reificação da própria reificação. Reificação é uma qualidade de todas as relações implícitas na expressão "casos de". Intimamente ligado ao problema dos "casos" está o problema das "dimensões". Para Honneth, não apenas existem casos de reificação: existem também dimensões, tais como aquelas rotuladas por ele de "intersubjetivas", "subjetivas" e "objetivas", cada uma das quais ligando uma forma particular de "falha no reconhecimento" - de outras pessoas, de si mesmo e da natureza, respectivamente. Deveria ser óbvio que uma ontologia normativa - uma "metafísica", para usar uma terminologia derrideana - sustenta tanto a utilidade quanto a "dimensionalidade" que Honneth atribui ao conceito de reificação". Esta "ontologia normativa" é precisamente o que Lukács chama de "reificação".

${ }^{11} \mathrm{O}$ mesmo deve ser observado sobre a noção idealista de Honneth do reconhecimento "antecedente" do outro, uma "posição ancorada profunda e culturalmente" que é "em seguida anulada" no esquecimento que Honneth chama de "reificação" (HONNETH, 2008, p. 155) Como todos os três comentadores de suas palestras apontam, Honneth não tem uma concepção de um primeiro encontro com o outro senão como algo benevolente. Judith Butler coloca-o do seguinte modo: "a dinâmica da subjugação e do medo da morte presente na discussão de Hegel sobre o reconhecimento na Fenomenologia do espírito não é encontrada em nenhum lugar na concepção [de Honneth] [...]" (id., p. 101). 
24 - Remate de Males 35.1

\section{REIFICAÇÃO COMO INSTRUMENTALIZAÇÃO}

Em que medida a crítica da reificação de Lukács é simplesmente uma crítica da própria relacionalidade sujeito-objeto? O conceito "fantasma da objetividade" estende-se a toda entidade aparentemente objetiva, ou apenas àquelas objetividades que são diretamente alcançadas nas relações das mercadorias? Em que ponto na escala da "totalidade" da reificação a análise marxista se funde a uma análise existencialista?

Sem dúvida, alguns leitores de Lukács hesitarão face à ideia de reificação aqui apresentada, uma vez que ela equaciona a reificação com o mundo objetivo. No início de seu ensaio sobre a reificação, Lukács insiste que o fetichismo da mercadoria deve ser considerado como um problema específico de nossa era, "a era do capitalismo moderno". A maioria dos comentadores sobre o tema da reificação concordaram com ele, ao menos retoricamente; e o próprio Lukács considerou impossível reconciliar tal princípio com uma aderência contínua ao conceito de reificação. "Quando associei alienação a objetificação", ele escreve em seu prefácio de 1967 a História e consciência de classe, explicando a sua renúncia ao seu conceito mais influente, "eu quis dizer isso como uma categoria social - o socialismo iria, afinal, abolir a alienação - mas a sua presença irredutível na sociedade de classes e sobre todas as suas bases na filosofia o trouxe para a proximidade da "condition humaine"” (LUKÁCS, 1971, p. 84, xxiv).

Estas questões sobre a relação entre representação e objetividade, ou entre o marxismo e o "existencialismo", estão no cerne do atual debate sobre a reificação. Por exemplo, o recente livro de Kevin Floyd, The reification of desire: toward a queer Marxism, publicado em 2009, argumenta que o que precisa ser combatido na conceitualização da reificação é a sua expansão "mística", uma "tendência metafisicalizante", que ele vê como tendo "assombrado esta "categoria ostensivamente marxista" desde o momento da escrita de Lukács (FLOYD, 2009, p. 19). Floyd procura reimpor um limite conceitual sobre o conceito, enquanto retém uma abertura face às suas "significações divergentes" (id., p. 25). A sua intenção é reconciliar a análise da reificação de Lukács - e, portanto, mais genericamente a crítica marxista-com a política queer. Como Honneth (embora ele tire conclusões diferentes), Floyd (2009, p. 21) entende o estudo original de Lukács como postulador de "algum movimento anterior, colocado retrospectivamente, de unidade social orgânica", do qual o fato da reificação registra um declínio. Para Lukács - na análise de Floyd, como na de Honneth - a reificação é um modo de representação; ela é exemplificada, para Floyd (2009, p.72), mais diretamente na "objetificação sexual do corpo". Floyd 
vê a crítica da objetificação de Lukács como subjacente a uma forma de "heteronormatividade" que "de modo implícito porém constitutivo exclui as práticas sexuais não-normativas” (id., p. 67). A teoria da reificação de Lukács parece especialmente problemática, portanto, "a partir da vantagem de uma política queer contemporânea que insiste na legitimidade, em espaços anti-heteronormativos, da objetificação sexual do corpo". A solução de Floyd para esta lógica supostamente humanista e transcendental é rejeitar inteiramente a inflexão negativa dada à categoria da reificação. Para ele,

a reificação torna possível uma multiplicidade de novas formas de subjetividade como prática social. Sujeitos qualitativamente diferentes, imprevisíveis, hétero e homossexuais desde o início se "estilhaçam" [...] da dialética unificadora de reconciliação que enquadra a análise de Lukács. Este novo domínio da prática e do discurso sexuais permanece tanto estruturalmente irredutível ao capital como imprevisivelmente determinado vis-à-vis o capital (Floyd, 2009, p. 75).

Esta concepção é influenciada pela brilhante análise de Foucault da "hipótese repressiva" na História da sexualidade, v. 1, onde Foucault aponta a qualidade potencialmente libertadora das categorias mesmas com as quais a psiquiatria do século XIX procurou disciplinar os desvios sexuais. O que Foucault chama de "solidificação regional" de várias perversões sexuais é precisamente o que as possibilitou adquirir visibilidade, para alcançar "uma realidade analítica [...] e permanente" (FOUCAULT, 1990, p. 44). Usando Foucault, então, Floyd rejeita a ideia de reificação como "razão instrumental" da Escola de Frankfurt, assim como a aproximação filosófica da reificação ao "pensamento da identidade" de Adorno. Qualquer "práxis genuinamente anti-heteronormativa”, diz Floyd (2009, p. 25), "deve incluir como objetivo a legitimação de instrumentalizações homossexuais do corpo". Lida à luz de Foucault, ele escreve, a reificação se torna "uma condição da possibilidade de uma nova forma de conhecimento crítico e anti-heteronormativo" (id., p. 74). Uma vez que reconhecemos que "regimes de conhecimento sexual têm efeitos sociais complexos", os quais podem ser tanto libertadores quanto repressivos, uma nova orientação frente à reificação como "uma abertura e também um encerramento de horizontes" torna-se possível.

Esta é uma tese ambiciosa e provocativa; Floyd está mais atento aos detalhes do argumento de Lukács do que Honneth, e seus instintos políticos são inquestionavelmente mais progressistas. De qualquer modo, a base de sua reorientação do conceito de reificação é a mesma compreensão reduzida do termo que encontramos em Honneth. Floyd 
- influenciado, sem dúvida, por alguns momentos ambíguos no ensaio de Lukács - entende a reificação como um drama antes representacional que ontológico. Portanto, quando escreve sobre a crítica do casamento de Kant como "o uso recíproco, feito por uma pessoa, dos órgãos e faculdades sexuais do outro", um trecho famoso do ensaio de Lukács, Floyd localiza o momento da reificação na "objetificação sexual" mútua, e não no aparato inteiro de organização social que Kant, com aquela "franqueza ingenuamente cínica peculiar aos grandes pensadores", segundo Lukács, chama de "comunidade sexual” (LUKÁCS, 1971, p. 100). Na leitura de Floyd, Lukács torna-se uma figura moralizante e humanizadora para quem as relações sociais reificadas, isto é, os modos reificados de percepção, são uma matéria subjetiva e eticamente evitável. O deslize é o mesmo de Honneth quando ele localiza a reificação nas relações de trabalho na atitude subjetiva, "antiética" do empregador em relação ao trabalhador (ou, por extensão, de qualquer um em relação a qualquer um), e não na estrutura social e econômica que inclui a produção do trabalhador enquanto tal. Embora Lukács fale sobre ambos os processos, ele é completamente claro em relação a qual deles conta como reificação. A marca da reificação é evidente "sobre a consciência inteira do homem", ele escreve, sobre "as profundezas da estrutura física e psíquica do homem”. A reificação nunca é perceptível em algum caso ou instância isolável e corrigível - o que significa que a reificação não é uma categoria ética em Lukács. A sua análise, como tenho enfatizado aqui, é mais bem lida como uma crítica, não da objetificação, mas da lógica da instanciação.

As repercussões deste deslize tornam-se aparentes quando Floyd se dirige à questão da subjetividade política. A categoria ausente na sua leitura do ensaio de Lukács é a da consciência de classe "imputada", digamos, a insistência de Lukács em que o "ponto de vista do proletariado" não é habitável por qualquer trabalhador específico, ou trabalhadores, do proletariado à frente do momento no qual as relações sociais reificadas são derrubadas (LUKÁCS, 1971, p. 51 e p. 74). Para Floyd, mesmo o termo "queer", em relação ao qual ele faz um investimento político considerável, é também "uma forma reificada de subjetividade", porque oferece "uma vantagem nas relações sociais abertas pela diferenciação corrente dessas relações pelo capital". A subjetividade queer, assim, "começa a revelar as limitações da concepção marxista padrão da reificação" (FLOYD, 2009, p. 25). Em Lukács, a consciência de classe, como a própria reificação, não é uma questão de representação ou representabilidade, mas uma lógica: uma formação cuja verdade ou validade não depende de sua realização. Floyd (2009, p. 75-76) rejeita esta distinção, insistindo em uma "leitura 
do conceito marxista de reificação que se recusa a situar tal conceito em uma teleologia da consciência de classe". Mas o que ele abandona, com esta negação, é a liberação de todos os termos e conceitos (incluindo a reificação) que é imanente ao conceito de reificação. Quando fala das qualidades "mistificadoras" dos trabalhos recentes sobre o tópico (em relação aos quais Floyd menciona este autor, que, a seu ver, "destaca a capacidade do conceito [...] para explicações metafísicas e religiosas" e também "endossa abertamente" a mesma tendência), sua análise é fixada ao significado dado de termos tais como religião, Cristandade, secularismo, casamento. A reversibilidade e mutabilidade de tais termos, em outras palavras, é simplesmente inacessível à leitura de Floyd (2009, p. 19-20 e p. 26) ${ }^{12}$.

\section{REPRESENTAÇÃO SEM INSTANCIAÇÃO}

Neste ponto, e sem ter dito tanto quanto estaria tentado a fazer para descreditar completamente a visão de Honneth sobre a reificação, ou para enumerar demais diferenças em relação a Floyd, retornarei à questão crucial da diferença entre representação e instanciação. Anteriormente, sugeri uma fórmula segundo a qual se pode descrever a possibilidade de uma representação não reificante: "representação sem instanciação", e gostaria de retornar a esta proposição.

A representação implica um certo modelo de relacionalidade entre o pensamento e o mundo objetivo; digamos, um modelo de consciência. Esta forma de relacionalidade está implicada no conceito de reificação definido por Lukács, de acordo com o qual o homem adota uma posição de "contemplação" face ao mundo objetivo: Lukács descreve isto como "o pensamento liberado da existência". Ele chama de "devir" (becoming) a forma de relação que ele coloca em oposição à anterior. O homem, ele escreve, "deve ter a faculdade de compreender o presente como

${ }^{12}$ Em Reification, or the anxiety of Late Capitalism, argumentei que a reificação só pode ser resgatada ou reanimada por meio da recuperação de sua qualidade enquanto uma lógica, e não como um processo social ou histórico. Entendido como lógica, o conceito de reificação não pode simplesmente ser aplicado ao mundo - como se outra existência não-reificada, desreificada ou prerreificada fosse concebível ou imaginável. A reificação também não pode ser considerada como um evento que, em algum sentido cronológico ou sociológico, realiza-se no isolamento do procedimento de observação e análise que nos permite detectar a sua operação. O próprio olhar analítico da crítica, o colocar em uso do conceito de reificação, nunca está livre da lógica da reificação. A reificação deve ser reconciliada com a imanência e separada de suas implicações humanistas. 
um devir. Ele pode fazê-lo observando no devir as tendências de cuja oposição dialética ele pode construir o futuro" (LUKÁCS, 1971, p. 203204). O devir, então, é o modo de consciência que Lukács, escrevendo em 1922, atribui ao próprio proletariado. Mas (e contra a visão de Floyd), o proletariado em Lukács não é um fenômeno instanciável; ele não é mais o "proletariado", na significação distinta do termo feita por Lukács, uma vez que tenha sido instanciado enquanto tal. Porque a reificação é uma lógica na qual o trabalhador, ou o objeto, entra em sua própria identidade, seu próprio ser. Na reificação o trabalhador assume o manto do ser; ele surge como indivíduo nomeável, desejante, perceptivo, "autônomo". É enquanto tal - enquanto um ser instanciado, instanciável - que ele é reificado. Na verdade, de qualquer modo, não se trata do fato de ele ser reificado (tal formulação o separa do próprio processo no qual ele passa a existir), mas de ser enlaçado, envolvido na reificação. Para ser mais preciso, trata-se menos do fato de ele estar implicado na reificação do que do fato de a reificação acontecer. Podemos ser ainda mais precisos se rejeitarmos todas essas formulações sucessivamente rarefeitas ou refinadas, já que a reificação, na verdade, não acontece. Se há reificação, o que ocorre na reificação não é a reificação, mas simplesmente o acontecer, o ter acontecido. Novamente (e contra Honneth), não existem "casos" de reificação, pois a lógica da reificação éa lógica do caso. Não há o acontecer da reificação, uma vez que a reificação não é senão o acontecer. Pelas mesmas razões, devemos insistir que não há um antes e um depois da reificação - já que a reificação é inseparável da lógica do antes e depois - isto é, da lógica da instanciação. O que o capitalismo alcança por meio da lógica da reificação não é a falsificação ou a má representação de qualquer coisa ou pessoa, mas a sua verdade, o seu vir a ser. $\mathrm{O}$ capitalismo não nos representa mal (como, por exemplo, mercadorias, coisas); ele nos instancia - não como algo que não somos, mas como quem somos. A lógica do capitalismo requer apenas que tudo e todos "se apresentem" em seu próprio nome. As "sutilezas metafísicas e as minúcias teológicas” que definem a mercadoria de Marx, na análise que dá a Lukács o seu modelo de reificação, não são nada além da existência autônoma dessa mercadoria, seu simples ser.

Tal é, então, a lógica burguesa do próprio capitalismo. A reificação, como Adorno e outros constataram, define e caracteriza a subjetividade capitalista como sendo tudo menos indetectável; é impossível diferenciar a nossa racionalidade, até mesmo a nossa utilização do conceito de reificação, da própria reificação. Não há, Lukács insiste, "nenhuma forma natural na qual as relações humanas podem ser moldadas, nenhuma maneira na qual o homem pode gozar de suas 'qualidades' físicas e 
psíquicas sem que elas sejam cada vez mais submetidas a este processo reificador" (LUKÁCS, 1971, p. 100) ${ }^{13}$.

Por contraste, na consciência do proletariado, diz Lukács, pensamento e existência "são aspectos de um e o mesmo processo histórico e dialético real" (id., p. 204). Não há nenhuma instrumentalidade no pensamento proletário, não porque os proletários não tendam a considerar outros seres humanos instrumentalmente, mas porque um proletário - no significado singular de Lukács do termo - não pode existir em uma relação contemplativa e autônoma em relação aos seus iguais. A consciência "proletária" não é habitável, nem conhecível, nem mesmo nomeável, sem que seja, deste modo, traída ou sem que a remoção do sujeito desta consciência seja assegurada.

\section{PLASTICIDADE E REIFICAÇÃO}

Em What should we do with our brain? (2004), Catherine Malabou faz uma pergunta retórica que se dirige diretamente a estas questões: "O que deveríamos fazer para que a consciência do cérebro não coincida pura e simplesmente com o espírito do capitalismo?" - A questão refere-se à representação. Como prevenir mesmo a nossa concepção de nós mesmos de ser implicada nos modos de conhecimento e instanciação que o capitalismo impinge sobre nós? Como representarmo-nos a nós mesmos sem reiterar a lógica da normatividade que, por exemplo, Luc Boltanski e Eve Chiapello (em um texto importante para Malabou) concebem como o "espírito" do capitalismo - o que eles chamam de seu "efeito de naturalização"? (MALABOU, 2008, p. 12; BOLTANSKI e CHIAPELLO, 2007, p. 149).

${ }^{13}$ Este é o próprio insight que Lukács iria, mais tarde, negar; mas, de modo significativo, o termo que ele usa para explicar sua crítica no prefácio de 1967 não é reificação, mas “objetificação", o que desloca completamente o primeiro termo no prefácio: "A objetificação é, de fato, um fenômeno que não pode ser eliminado da vida humana em sociedade. Se levarmos em conta que cada externalização de um objeto, na prática [...] é uma objetificação, que cada expressão humana, incluindo a fala, objetifica pensamentos e sentimentos humanos, então fica claro que estamos lidando com um modo universal de comércio entre homens. E desde que o caso é este, a objetificação é um fenômeno neutro; o verdadeiro é tanto uma objetificação quanto o falso, liberdade tanto quanto escravidão" (LUKÁCS, 1971, p. xxiv). O grau ao qual a reificação é retroativamente transformada no próprio pensamento de Lukács de um fenômeno puramente lógico em um fenômeno representacional está claro a partir do que segue imediatamente: "Apenas quando as formas objetificadas na sociedade adquirem funções que levam a essência do homem ao conflito com sua existência, apenas quando a natureza do homem é subjugada, deformada e aleijada, podemos falar de uma condição social objetiva de alienação" (id., p. xxiv). 
A resposta de Malabou toma a forma da elaboração de um conceito. Para ela, a plasticidade designa aquela função e qualidade do cérebro que é hostil ao espírito do capitalismo, isto é, à propensão à instanciação. A plasticidade, na conceitualização de Malabou, é nada menos que a contraparte material da filosofia do devir. Ela é, a autora escreve, o "antônimo exato" da rigidez. A plasticidade não pode ser conhecida, muito menos instanciada. Para Malabou, "Humanos fazem seus próprios cérebros, mas não sabem que o fazem. Nosso cérebro é fruto de um trabalho, e não temos noção disso. $O$ nosso cérebro é plástico, e não sabemos disso" (MALABOU, 2008, p. 12). A plasticidade significa tanto receber forma quanto dar forma, o que quer dizer que descrever o cérebro como "plástico" é, na verdade, dar fim à noção de cérebro enquanto entidade ontologicamente limitada ou determinada. Como os nossos "desejos e intenções", ou como a própria sociedade, o cérebro é fruto de um trabalho; ele não existe, ou antes, a plasticidade é o seu modo de existência. Malabou (2008, p. 9) continua:

\begin{abstract}
Claramente, se não temos consciência da plasticidade é porque, de acordo com um paradoxo meramente aparente, a plasticidade nos é tão familiar que nem mesmo a enxergamos; não notamos sua presença, como um ambiente no qual nos mantemos e evoluímos sem lhe prestar atenção. Ela se tornou a forma do nosso mundo.
\end{abstract}

A plasticidade é, diga-se, representável mas não instanciável; a plasticidade é perdida, traída, no momento em que é instanciada. O que a plasticidade denota, ademais, é o próprio princípio da instabilidade, isto é, o devir, o tornar-se.

Consideramos instrutivo comparar o raciocínio de Malabou com o de um recente ensaio de Quentin Meillassoux, que escreve, não sobre reificação ou plasticidade, mas sobre a imanência:

Sabemos que, de acordo com Deleuze, a imanência de algum modo "satura" a filosofia de Spinoza. Tudo em Spinoza, Deleuze nos diz, respira imanência. Mas dizer que a imanência está em toda a parte em Spinoza é torná-la difícil de se perceber, como uma luz difusa: se está em todo lugar, então não está em nenhum lugar em particular. Esta é a razão pela qual a tentativa de entender a imanência deleuziana com base em Spinoza não lhe será muito proveitosa (MEILLASSOUX, 2007, p. 66).

Para Meillassoux, a imanência é compreendida mais facilmente quando se lê Bergson do que quando se lê Spinoza, pois em Bergson há um "diferencial de imanência". A imanência acontece "uma vez e apenas uma vez" em Bergson, no primeiro capítulo de Matéria e memória, no qual 
Bergson apresenta a teoria da "percepção pura”: uma teoria queéverdadeira "em princípio, mas não de fato". Depois deste "pico" no pensamento de Bergson, Meillassoux (2007, p. 66-68) observa, a imanência "se esvai"; nada no resto do texto de Matéria e memória se iguala à sua "satisf[ação]" das condições de imanência no primeiro capítulo.

A explicação de Meillassoux do problema da imanência, em seu ensaio, contrapondo Bergson e Spinoza, é útil para ilustrar a problemática da reificação, a qual, como tenho argumentado neste ensaio, precisa ser teorizada nos mesmos termos: como um conceito cindido no paradoxo que para reconhecê-lo, fazer uso dele, já é enfraquecer sua força conceitual. De qualquer modo, a rota que Meillassoux segue em sua própria investigação está fadada ao fracasso, por razões que são também esclarecedoras para o conceito de reificação. Meillassoux contempla o seu artigo como uma tentativa de construir ou "modificar" a teoria de Bergson da percepção pura, de tal modo que a imanência bergsoniana possa ser dita como verdadeira "não apenas em princípio, mas também de fato". Tal projeto envolverá a reconciliação da categoria "hipotética" de Bergson (percepção pura) com a sua instanciação (percepção humana real). Ao contrário, então, de tudo que Bergson insiste sobre a situação "hipotética" da percepção pura no primeiro capítulo de Matéria e memória, Meillassoux enfraquece a "imanência" em algo como a possibilidade da intuição da matéria como ela existe "em si mesma"; ele, deste modo, reintroduz o componente subjetivo na imanência. No pensamento de Meillassoux, a imanência existe como uma categoria que, ao menos na teoria, é capaz de ser "satisfeita" (isto é, instanciada). Segundo Meillassoux, a mesma contradição está presente no raciocínio de Bergson quando, no segundo capítulo de Matéria e memória, Bergson vai do conceito de percepção pura ao problema da memória, o qual, como ele aponta, está sempre presente em qualquer percepção real. Não obstante, Bergson é muito cuidadoso ao diferenciar sua noção da "imagem de memória" examinada no segundo capítulo da "memória pura” que é uma categoria "hipotética" e, como tal, inacessível à percepção da mente humana. No decorrer do ensaio de Meillassoux, a proposta de Bergson das "imagens nelas mesmas", como Deleuze a caracteriza, é tão marginalizada quanto a noção de percepção pura/ memória pura (BERGSON, 1988, p. 67; DELEUZE, 1986, p. 6o). Como na leitura de Lukács feita por Honneth, portanto, Meillassoux transpõe a teoria da percepção subtrativa de Bergson do registro lógico para o registro representacional. Por contraste, a teoria de Bergson, na qual 
a percepção pura e a memória pura apresentam-se como categorias virtuais das quais nossas próprias percepções e memórias sempre são "subtraídas" é essencialmente uma teoria não-humana da percepção; estas hipóteses - veículos de imanência, como Meillassoux intui - são não instanciáveis e, por isso, em efeito, inacessíveis. A percepção pura de Bergson não pode ser instanciada - não pode ser tornada verdadeira "de fato" - sem ser relacionada a um "centro de indeterminação" (um sujeito), ao longo do qual sua pureza não pode evitar ser dissolvida na percepção subtrativa de um indivíduo ${ }^{14}$.

A discussão de Bergson feita por Meillassoux é cercada por várias condições idiossincráticas adicionais, a mais significante das quais sendo a decisão de não prestar nenhuma atenção aos livros sobre cinema de Gilles Deleuze, o local dos comentários mais consequentes de Deleuze sobre a teoria da percepção de Bergson, com base no fato de que é mais "interessante" - ou leva a maior "compreensão" - tentar "reconstruir" um filósofo que "interpretá-lo" (MEILLASSOUX, 2007, p. 69). A importância dos estudos de Deleuze sobre cinema, entretanto, não se resume a um contexto de seu pensamento sobre a imanência; o cinema, antes, oferece um substrato material para o tempo-imagem, um substrato que não faz referência à percepção subtrativa (humana). Para Deleuze, em outras palavras, é precisamente o cinema - "o em-si da imagem", como ele o denomina - que torna a "percepção pura” de Bergson verdadeira em "princípio" tanto quanto "de fato", pela mera presença do aparato maquinal - a câmera. A escolha de Meillassoux da "reconstrução" sobre

${ }^{14}$ Em um ponto revelador de seu ensaio, Meillassoux (2007, p. 73) distingue dois momentos de seleção na teoria da percepção de Bergson: o primeiro, "pelo corpo", é uma seleção feita "não livremente"; o segundo, "pela mente", é uma escolha feita livremente, "pelos elementos perceptivos anteriormente selecionados pelo corpo a partir da infinidade de imagens". Ao diferenciar estes dois momentos, entretanto, Meillassoux está restabelecendo a distinção mesma que a teoria da percepção de Bergson não mais permite, a distinção cartesiana e/ou berkeleyana (entre corpo e mente) contra a qual a teoria da percepção inteira foi proposta. Ademais, sua descrição da percepção bergsoniana termina com a réplica da mesma falácia das "dimensões" que encontramos na acepção de Axel Honneth da reificação lukacsiana. Como Honneth, Meillassoux identifica "três realidades no âmbito da percepção: matéria, corpo, mente" (id., p. 74). Com este movimento em seu argumento, Meillassoux simplesmente descarta o que é essencial na teoria de Bergson da percepção pura, a sua qualidade "hipotética" - assim como Honneth, com a sua diferenciação entre reificação "intersubjetiva", "subjetiva" e "objetiva”, descarta o que é essencial à teoria da reificação de Lukács: a sua qualidade enquanto lógica. Na teoria de Bergson não há dois princípios de seleção sendo desenvolvidos, mas um; assim como nenhuma diferenciação em "realidades" é possível ou necessária na "percepção pura”: há apenas imagens, a agregação das quais formando a consistência que Deleuze irá, mais tarde, chamar de "plano de imanência". 
a "exegese", uma preferência cuja base lógica - verdadeira "compreensão", verdadeiro "interesse" - parece ser primariamente subjetiva, significa que o seu projeto de reconciliar a hipótese da percepção pura com a sua realidade é levada por uma rota teórica que só pode terminar onde de fato termina: em uma oscilação dolorosa, perpétua entre instanciação e a euforia do devir, entre a descida na reificação e a dissolução assustadora do sujeito. O "princípio" da percepção pura bergsoniana não pode ser reconciliado com o "fato" enquanto a medida de sua facticidade mantém a sua instanciabilidade em percepção subjetiva.

Como a visão de Malabou sobre a plasticidade e a visão de Meillassoux sobre a imanência deleuziana, o modelo de reificação que estou tentando extrair a partir do trabalho pioneiro de Lukács é tanto incomensurável com a instanciação do conceito (isto é, com o próprio conceito), quanto inseparável dele. É por esta razão que (como argumentei alhures) a fidelidade de Lukács a seu próprio conceito é mais expressa que traída em sua renúncia ao próprio conceito (BEWES, 2002, p. xvi) ${ }^{15}$.

"Pensar é sempre esquematizar", escreve Malabou (2010, p. 13). Como podemos pensar, p. ex., representar o mundo para nós mesmos, sem esquematizar? Em particular, quando o mundo no qual vivemos impulsiona tudo em direção à autoexpressão, isto é, autopossessão, como pensar até mesmoesta tendência semalargá-ladesproporcionalmente? Comoevitamos tornar a própria reificação, agora reenquadrada como instanciação, naquilo que Malabou chama de o "esquema motor hermenêutico de uma época"? (id. ibid.) A plasticidade, Malabou escreve em O futuro de Hegel (L'avenir de Hegel), "é a 'instância' que dá forma ao futuro e ao tempo na filosofia de Hegel” (MALABOU, 2005, p. 5). Para ela, o conceito de plasticidade é um meio pelo qual o processo de conceitualização, o próprio dar forma, pode ser

15 Estou seguindo, aqui, um princípio articulado por Louis Althusser no capítulo de abertura de Ler o capital, no qual ele escreve que um "conceito antigo" (o exemplo dado é a persistência de categorias hegelianas nos escritos de Marx) pode, às vezes, fazer o papel de algo ausente, chamando-o "para o palco em pessoa" - tornando aparente uma entidade sem nome precisamente na "deslocação entre os personagens em seus papéis" (ALTHUSSER, 2009, p. 31). Cf. também a obra de Jacques Rancière, aluno, coautor e detrator de Althusser, tendo escrito no prefácio a $O$ filósofo e seus pobres que "qualquer modo de pensamento que é minimamente singular se revela por dizer basicamente sempre a mesma coisa, algo que não pode senão sempre arriscar no prisma colorido das circunstâncias" (RANCIĖRE, 2003, p. xxviii). Ao seguir e combinar estes dois raciocínios, proponho que entendamos a teoria da reificação de Lukács como dizendo "basicamente a mesma coisa" que a sua posterior renúncia a ela; que a diferença entre a elaboração do conceito e o repúdio a ele não é nada além de uma diferença de "circunstâncias", no sentido que Rancière dá ao termo - ou a diferença entre o personagem e seu papel, para usar a imagem de Althusser. 
repensado como aquele que resiste à instanciação dado à inseparabilidade de seus dois significados: dar e receber forma. O que é crucial ao conceito de plasticidade é a sua própria plasticidade - justamente o que é crucial ao conceito de reificação é a sua própria suscetibilidade à reificação, sua habilidade para registrar tal suscetibilidade. Ambos os termos mantêm uma estrutura dialética inerente. O insight adicional de Malabou (2005, p. 11-12 e p. 18) é que a plasticidade é ainda mais crucial à filosofia de Hegel devido à "escassez de referências" a ela na própria escrita de Hegel. Para Malabou, a plasticidade responde à questão de como representar a lógica do capitalismo sem instanciá-lo. Como a reificação, da qual a plasticidade é o anverso, a plasticidade é ao mesmo tempo um conceito e um modelo de conceitualização; é tanto uma representação quanto um modelo de representação (representação sem instanciação). Uma versão de plasticidade que é compatível com a lógica do capitalismo existe, mas, por contraste, não tem plasticidade. Como Malabou diz, a forma reconhecível de plasticidade é a "flexibilidade": a plasticidade nomeada, instanciada, abstraída. A flexibilidade, Malabou (2008, p. 12) escreve, é "a plasticidade menos o seu gênio", o seu "avatar ideológico". O gênio da plasticidade é a sua própria plasticidade; e podemos afirmar o mesmo sobre a reificação: o gênio da reificação, enquanto conceito, é a sua reificabilidade, sua reflexibilidade, seu inerente reconhecimento da lógica que a impulsionaria para o mundo da representação, tornando-a, digamos, uma "desumanização" ou "falha no reconhecimento". Essa lógica instancia tais termos, conferelhes um significado referencial, quebra-os em "aspectos" ou "dimensões" (HONNETH, 2008, p. 76-77; MEILLASSOUX, 2007, p. 77), transformaos em qualidades, ou eventos interpessoais. Desta maneira, a tendência do capitalismo é transpor a plasticidade do ser, isto é, o tornar-se, para a existência inerte, reificada.

Enquanto isso, para retornar para uma figura à qual me referi rapidamente, a fidelidade de Louis Althusser ao conceito de reificação foi tão completa que ele nunca a abordou; na verdade, ele aproveitou toda oportunidade que teve para descreditá-la. A reificação é tão difícil de ser percebida na filosofia de Althusser quanto a imanência o é na de Spinoza; mas é exatamente nesta capacidade que a ideia "satura" o seu pensamento. O conceito de reificação de Althusser é mais consistente que o de Lukács, apesar ou exatamente por causa do fato de ele nunca deixar de rebaixar o termo. A utilidade do ensaio de 1922 sobre reificação de Lukács, em comparação, vem do fato de que, como o conceito de plasticidade de Malabou, e como a leitura da imanência em Bergson 
feita por Deleuze, ele permite a teorização do conceito em virtude de sua dissolução parcial na forma de sua instanciação. No encontro entre "a reificação e a consciência do proletariado" e sua posterior renúncia ao conceito, Lukács nos fornece um "diferencial” da reificação. Tomados em conjunto, os dois momentos permitem a sua reconceitualização em termos de instanciação.

Traduzido por Aline Zouvi

\section{REFERÊNCIAS BIBLIOGRÁFICAS}

ALTHUSSER, Louis. For Marx. Trad. Ben Brewster. Londres: Verso, 2005.

ALTHUSSER, Louis; BALIBAR, Étienne. Reading Capital. Trad. Ben Brewster. Londres: Verso, 2009.

BADIOU, Alain. The Century. Trad. Alberto Toscano. Cambridge: Polity, 2007.

BELTANSKI, Luc; CHIAPELLO, Ève. The New Spirit of Capitalism. Trad. Gregory Elliott. Londres: Verso, 2007.

BERGER, Peter; LUCKMANN, Thomas. The Social Construction of Reality: a treatise in the Sociology of knowledge. Nova Iorque: Anchor, 1967.

BERGSON, Henri. Matter and Memory. Trad. Nancy Margaret Paul e W. Scott Palmer. Nova Iorque: Zone, 1988.

BEWES, Timothy. Reification, or the anxiety of Late Capitalism. Londres: Verso, 2002.

BROWN, Bill. Reification, reanimation, and the american uncanny. In: Critical Inquiry, 32, p. 175-207, inverno de 2006.

DELEUZE, Gilles. Cinema 1: the movement-image. Trad. Hugh Tomlinson e Barbara Habberjam. Londres: Athlone, 1986.

FEENBERG, Andrew. Rethinking Reification. In: BEWES, Timothy; HALL, Timothy (eds.). Georg Lukács: the fundamental dissonance of existence. Londres: Continuum, 2011.

FLOYD, Kevin. The Reification of Desire: toward a queer Marxism. Minneapolis: University of Minnesota Press, 2009.

FOUCAULT, Michel. The history of Sexuality: an introduction. V. 1. Trad. Robert Hurley. Harmondsworth: Penguin, 1990.

GABEL, Joseph. False Consciousness: an essay on reification. Trad. Margaret A. Thompson (com assistência de Kenneth A. Thompson). Nova Iorque, Evanston, San Francisco: Harper and Row, 1975 . 
36 - Remate de Males 35.1

HEIDEGGER, Martin. Being and time. Trad. John Macquarrie e Edward Robinson. Oxford: Blackwell, 1962.

HONNETH, Axel. Reification: a new look at an old idea. Trad. Joseph Ganahl. Oxford: Oxford University Press, 2008.

HONNETH, Axel. Verdinglichung: eine anerkennungstheoretische studie. Frankfurt: Suhrkamp, 2005.

JAMESON, Fredric. Valences of the dialectic. Londres: Verso, 2011.

JAMESON, Fredric. Representing capital: a commentary on volume one. Londres: Verso, $2011 b$.

KOPYTOFF, Igor. The cultural biography of things. In: APPADURAI, Arjun. The social life of things. Cambridge: Cambridge University Press, 1986.

LARSEN, Neil. Lukács sans proletariat, or can History and class consciousness be rehistoricized? In: BEWES, Timothy; HALL, Timothy (eds.). Georg Lukács: the fundamental dissonance of existence. Londres: Continuum, 2011.

LUKÁCS, Georg. History and class consciousness: studies in marxist dialectics. Trad. Rodney Livingstone. Londres: Merlin, 1971.

MALABOU, Catherine. What should we do with our brain? Trad. Sebastian Rand. Nova Iorque: Fordham University Press, 2008.

MALABOU, Catherine. The future of Hegel: plasticity, temporality and dialectic. Trad. Lisabeth During. Londres e Nova Iorque: Routledge, 2005.

MALABOU, Catherine. Plasticity at the Dusk of writing: dialectic, destruction, deconstruction. Trad. Carolyn Shread. Nova Iorque: Columbia University Press, 2010.

MARX, Karl. Capital: a critique of political economy. V. 1. Trad. Ben Fowkes, Harmondsworth: Penguin, 1990.

MARX, Karl. The communist manifesto. Ed. Frederic L. Bender. Nova Iorque: Norton, 1988.

MEILLASSOUX, Quentin. Subtraction and contraction: Deleuze, immanence, and matter and memory. In: MACKAY, R. (ed.). Collapse III. Falmouth: Urbanomic, nov. 2007.

RANCIÈRE, Jacques. The philosopher and his poor. Trad. John Drury, Corinne Oster, e Andrew Packer. Durham and London: Duke University Press, 2003.

RANCIÈRE, Jacques. The future of the image. Trad. Gregory Elliott. Londres: Verso, 2007.

ŽIŽEK, Slavoj. Postface: Georg Lukács as the philosopher of Leninism. In: LUKÁCS, Georg. A defence of History and class consciousness: Tailism and the dialectic. Trad. Esther Leslie. Londres: Verso, 2000. 
ŽIŽEK, Slavoj. Žižek in Wall Street - Transcript. Disponível em: http://www. criticallegalthinking.com/?p=4415\#more-4415. Acesso em: 14/10/2011a.

ŽIŽEK, Slavoj. We are not dreamers, we are the awakening from a dream which is turning into a nightmare. Disponível em: http://www.versobooks.com/blogs/736-slavojzizek-at-occupy-wall-street-we-are-not-dreamers-we-are-the-awakening-from-adream-which-is-turning-into-a-nightmare. Acesso em: 14/10/2011b.

ŽIŽEK, Slavoj. Welcome to the Desert of the Real: five essays on september 11 and related dates. Londres: Verso, 2002. 